\title{
Capital Social e Sistema Único de Saúde (SUS) no Brasil
}

\section{Social Capital and the National Health System (SUS) in Brazil}

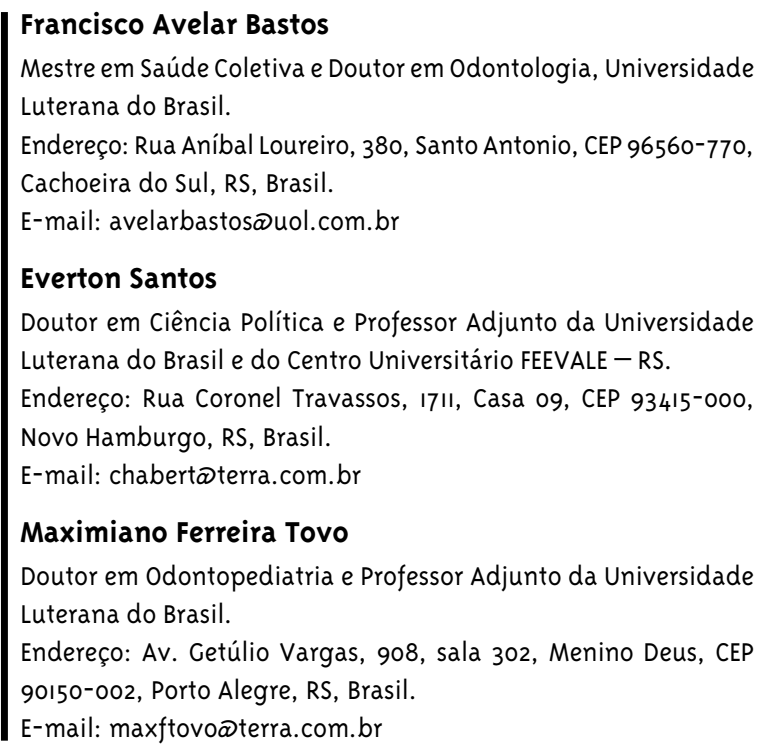

E-mail: maxftovoळterra.com.br

\section{Resumo}

O objetivo principal deste artigo é construir um referencial teórico preliminar que possibilite a compreensão das razões que podem determinar o desempenho satisfatório das instituições de saúde no Brasil, particularmente o do Sistema Único de Saúde (SUS). A hipótese teórica, a partir dos estudos de Putnam (2005), é de que o acúmulo de Capital Social (CS) em determinada sociedade está positivamente relacionado à capacidade de os governos atenderem e realizarem as demandas da população. Em outras palavras, os níveis de solidariedade e de confiança interpessoais e a existência de organizações sociais são elementos colaborativos para o desempenho das instituições políticas. O CS, na área da saúde, funcionaria como elemento de impacto positivo, não somente pelo fato de proporcionar uma vida mais saudável para as populações, reduzindo a exclusão social e aumentando a longevidade e a autoestima, mas também por ter um papel fundamental no estímulo da participação da comunidade tanto na formulação de políticas públicas como no seu controle social, o que possibilitaria o melhor funcionamento das instituições. Nesse sentido, utilizamos os dados de pesquisa quantitativa aplicados em usuários do SUS em duas cidades do Rio Grande do Sul (Caxias e Pelotas).

Palavras-chave: Capital social; Sistema Único de Saúde; Controle social. 


\section{Abstract}

The main objective of this paper is to construct a preliminary theoretical framework that enables the understanding of the reasons that may determine the satisfactory performance of health institutions in Brazil, particularly that of the National Health System (SUS). Based on the study of Putnam (2005), the theoretical hypothesis is that the accumulation of Social Capital (SC) in a certain society is positively related to the governments' ability to meet the population's demands. In other words, the levels of interpersonal solidarity and trust and the existence of social organizations collaborate with the performance of the political organizations. In the health area, SC would work as an element of positive impact, not only because it offers a healthier life to populations, reducing social exclusion and increasing longevity and self-esteem, but also because it plays a fundamental role in the stimulation to community's participation, both in the formulation of public policies and in their social control, which would enable the better functioning of the institutions. In this sense, we used data from a quantitative research study applied to SUS users in two cities of the state of Rio Grande do Sul (Caxias and Pelotas).

Keywords: Social Capital; National Health System; Social Control.

\section{Introdução}

Nas últimas décadas, com o processo de redemocratização no Brasil, assistimos a um avanço político institucional inegável. De maneira geral, as eleições tornaram-se rotineiras, e as liberdades políticas de organização e de participação têm adquirido importância central. Todavia, nem sempre os avanços políticos institucionais significaram, na mesma proporção, uma melhora efetiva e progressiva das condições de vida da população brasileira. Havia a crença de que a democratização traria rapidamente a felicidade nacional. Entretanto, convivendo majoritariamente com os partidos, o parlamento e as eleições, os governantes brasileiros têm se deparado com uma demanda crescente da sociedade sobre as instituições do Estado e consequentemente de suas políticas públicas. Esse é um fenômeno típico de sociedades democráticas, em que as "comportas" que represavam a pressão social sobre o Estado durante os tempos pretéritos do autoritarismo, como a brasileira, foram abertas.

Assim, uma das grandes questões, impostas à agenda do governo, neste início de século, é exatamente sua eficiência e capacidade em atender às demandas provenientes dessa sociedade: promover a segurança, criar empregos e, particularmente tratada neste artigo, atender à saúde da população. Isso remete ao questionamento das variáveis determinantes do desempenho satisfatório das instituições do Estado, além, é claro, da capacidade dos governantes em implementá-las e formulá-las. Também à medida que as condições societais influenciam o bom desempenho das instituições de saúde. Em relação a isso, especialmente, interessa compreender a atuação do Sistema Único de Saúde (SUS) no Brasil, criado a partir da Constituição de 1988.

A hipótese deste artigo, a partir dos estudos de $\mathrm{Pu}$ tnam (2005), é de que o acúmulo de capital social (CS) em uma determinada sociedade, está positivamente relacionado à capacidade de os governos atenderem e realizarem as demandas da população. Em outras palavras, os níveis de solidariedade e de confiança interpessoais e a existência de organizações sociais são elementos colaborativos para o desempenho das instituições políticas, razão pela qual as políticas públicas devem ser arquitetadas no sentido de estimular o acúmulo de CS. Assim, o capital social na área da saúde funcionaria como um elemento de impacto positivo, 
não somente pelo fato de proporcionar uma vida mais saudável para as populações, reduzindo a exclusão social e aumentando a longevidade e auto-estima, mas também por ter papel fundamental no estímulo da participação da comunidade tanto na formulação de políticas públicas como no seu controle.

Nesse sentido, a Conferência de Alma-Ata apontou a necessidade da construção de um novo modelo, calcado na Atenção Primária à Saúde, através de cuidados essenciais, baseados em métodos e tecnologias práticos, cientificamente bem fundamentados e colocados à disposição das comunidades de maneira universal. No Brasil, essas ideias foram incorporadas pelo Movimento da Reforma Sanitária, que as levaram SUS e a uma nova conformação do Estado brasileiro (Bastos, 2005).

Nesse contexto, invariavelmente, situa-se a necessidade do "controle social" a partir de um dos princípios do SUS, ou seja, a capacidade que a sociedade organizada tem de interagir com o Estado para o estabelecimento de seus interesses e de suas necessidades, o que se dá através dos conselhos e das conferências de saúde, embasados em uma legislação infraconstitucional dentro de uma prática mais ampla de democratização e de descentralização do Estado, buscando quebrar uma tradição autoritária e clientelística, ligada à formação de um Estado patrimonialista. Todavia, esse "controle social" apresenta limites pela forma de configuração das relações entre Estado e Sociedade no Brasil ao longo de seu processo histórico de conformação em que a preponderância daquele, pela ausência de capital social, retardou a dinamização e a organização desta em certo sentido.

Dessa forma, o objetivo principal deste artigo é construir um referencial teórico preliminar que possibilite compreender as razões que podem determinar o desempenho satisfatório das instituições de saúde no Brasil, ou seja, os mecanismos de infraestrutura social que permitem aos governos realizar seus propósitos de melhorar a qualidade de vida de sua população.

Este artigo justifica-se pelo argumento de que corroborar a hipótese da relação entre CS e desempenho institucional na saúde significa demonstrar que o sucesso das reformas políticas, como a criação do SUS na década de 1980, está relacionado não somente à qualidade das leis, das instituições e dos governos que as implementam, mas também à qualidade do tecido social no qual elas são implantadas. Essa hipótese, subvertendo, de certa forma, o argumento da virtude pública dos governantes, quer chamar a atenção para as configurações estruturais que estão na base do sucesso dos governos, seu peso na determinação da relação com os fatores conjunturais e institucionais.

Sendo assim, no primeiro tópico, O Estado Hegemônico, será discutida, brevemente, a formação do Estado no Brasil, optando pela perspectiva teórico-metodológica, segundo a qual o Estado, anterior à sociedade, organiza-a, moldando suas feições e idiossincrasias. No Brasil, a presença do Estado foi determinante para a configuração da sociedade, principalmente pelo fato de que, com a ausência de uma sociedade organizada, forte e horizontalizada e, portanto, portadora de CS, ele assumiu um papel protagonista na promoção do desenvolvimento local. Com a importação de instituições ibéricas, houve uma verticalização das relações entre Estado e sociedade, configurando-se uma relação de dominação, que a bibliografia especializada chama de patrimonialismo.

No segundo tópico, Vários Conceitos de Capital Social, serão discutidos, brevemente, os diferentes conceitos de capital social que aparecem na bibliografia a partir do século XIX, de forma implícita em autores como Durkheim, Marx, Tocqueville, Simmel, ou de forma explícita em autores contemporâneos como Pierre Bourdieu ou mesmo James Coleman. 0 tópico será finalizado com a explicitação da opção epistêmica pelo conceito de capital social por Robert Putnam e Fukuyama, como elemento-chave para o desenvolvimento cívico da comunidade e, consequentemente, das instituições políticas.

Finalmente, no terceiro tópico, Capital Social e Controle Social no SUS, será discutida a relação existente entre capital social e controle social do SUS. Esse tópico ressalta o fato de que a Constituição de 1988 e a Reforma Sanitária no Brasil abriram novas perspectivas e desafios para a sociedade, uma vez que os canais abertos para a participação popular se constituíram num fator importante para a qualificação dos serviços públicos e, consequentemente, para uma distribuição mais equânime dos serviços públicos no país. Isso exigiu um "controle social" sobre suas esferas de atuação, que estão diretamente implicadas na capacidade de acúmulo de capital social pela sociedade brasileira. Nessa perspectiva, analisamos os 
dados de duas pesquisas (tipo survey) realizadas com moradores de Caxias do Sul e Pelotas, duas cidades do Rio Grande do Sul, usuários do SUS, objetivando levantar dados empíricos iniciais que apontem nossa hipótese de trabalho.

\section{O Estado Hegemônico}

Neste artigo, utilizou-se, como pressuposto teórico, a ideia amplamente respaldada nas Ciências Sociais, contemporânea e, particularmente, mais adequada à compreensão do processo político brasileiro, de que a formação do Estado no Brasil precede a da sociedade. Em outras palavras, de que o Estado brasileiro, como importação europeia, configurou-se como entidade anterior, forte e robusta, que foi paulatinamente amalgamando a sociedade, portanto, criando-a no novo mundo (Faoro, 1979; Ferraz, 1993; Schwartzman, 1988).

Esse Estado, em sua anterioridade, cria a sociedade, quer seja através da concessão de terras, instituindo uma "aristocracia rural", quer seja através da concessão de financiamentos e de créditos para empreendimentos comerciais, criando burguesias locais, ou mesmo na concessão e na criação de inúmeros empregos públicos, possibilitando, nos diferentes rincões, a proliferação de uma classe média de origem estatal (Rouquié, 1984). De fato, o Estado configura-se como um "núcleo estrutural hegemônico" em relação à sociedade, articulando em seu entorno os demais sistemas. É no sistema econômico, por exemplo, que o Estado fixa os limites da liberdade de iniciativa econômica, apropriando-se de recursos da sociedade, no sistema político. A própria atividade política começa e termina em função da disputa de poderes legais e econômicos conferidos pelo Estado e através do sistema social e cultural em que acontece a divulgação de valores, ideias, atribuição de prestígio e distribuição de serviços por parte do Estado (Ferraz, 1993). Tudo se dá no entorno desse ente político. Todavia, essa configuração estatal, organiza a sociedade de maneira desigual, não só pelo fato de que possibilita aos grupos dominantes locais espaços de poder privilegiado, mas também porque distribui recursos e serviços desse Estado como educação, saneamento básico e, principalmente, saúde, de maneira desigual, ao longo da sua formação e estruturação.
É assim que o Estado, com uma estrutura sobreposta (forte), que gerencia os demais sistemas, e relativamente independente de uma sociedade desarticulada e atomizada (fraca), gera a formação de um tipo de dominação tradicional que a bibliografia chama de patrimonialismo. Este conceito é utilizado de uma forma geral para:

[...] caracterizar a apropriação privada dos recursos do Estado, seja pelos políticos ou funcionários públicos, seja por setores privados. Como tal contrapõe-se a um tipo ideal de sociedade liberal ou moderna na qual o Estado está separado do mercado, em que as burocracias funcionam de acordo com regras universais e o governo expressa os projetos das representações políticas constituídas a partir da sociedade civil (Sorj, 200o, p. 13).

Simon Schwartzman (1988) usa o termo "neopatrimonialismo" para se referir a um tipo de patrimonialismo moderno, uma vez que o termo originalmente utilizado por Weber estava ligado às formas típicas de dominação tradicional. Esse conceito de dominação política captura melhor a dimensão do processo de modernização do Estado, que combina a manutenção de estruturas de tipo tradicional com estruturas modernas.

De acordo com Sorj (2000), se, caso o Estado brasileiro fosse somente patrimonialista, o Brasil estaria condenado ao atraso, o que as altas taxas de crescimento econômico do século XX não confirmam. Dessa forma, o conceito de neopatrimonialismo aplica-se mais adequadamente a sociedades, como a brasileira, que transitaram ou que procuram transitar de formas tradicionais de dominação política para formas modernas, cujo resultado é um hibridismo entre o moderno e o tradicional.

Esse hibridismo manifestou-se politicamente em maior ou menor grau nos diferentes países latinoamericanos, com a importação de instituições verticais ibéricas, que organizaram essas sociedades de maneira vertical, estabelecendo laços de lealdade e de fidelidade, diferentemente do caso norte-americano, em que as instituições inglesas organizaram a sociedade de maneira horizontal, possibilitando laços de solidariedade e de confiança. Essas instituições políticas configuraram um modelo de "colonização de exploração", como argumenta Ribeiro (2005), em que o conjunto das riquezas aqui produzidas escoava para fora, ao passo 
que, no caso norte-americano, onde predominaram as “colônias de povoamento", as riquezas permaneciam.

Não se trata de apontar unicamente fatores exógenos para se aplicar as condições e desenvolvimento desses países, haja vista as condições precárias em que diferentes Estados latinos (em maior ou menor grau) têm atendido suas populações, sobretudo os mais pobres, nos serviços básicos de infraestrutura. Neste artigo, procura-se ressaltar que os fatores endógenos, mesmo que não sejam os únicos determinantes, podem influir na melhora das condições de vida e de saúde das populações. Em outras palavras, refere-se aos fatores determinantes internos que podem influir na melhora do desempenho do Estado, particularmente de suas instituições públicas, da democracia, enquanto regime político, e de suas consequências sobre o desenvolvimento das populações. Que fatores podem estar determinando o melhor ou pior desempenho das instituições, ou, de outra forma, que fatores podem facilitar as ações governamentais de maneira mais ampla? Quanto as instituições políticas dependem da qualidade de seus cidadãos?

As respostas a essas questões são bastante controversas, pois a bibliografia especializada tem se bifurcado basicamente em duas vertentes para explicar como um governo pode ter seu bom desempenho institucional melhorando suas relações com a sociedade. Há uma vertente teórica que dá ênfase aos aspectos políticos institucionais do Estado, chamando atenção para o fato de que um bom desempenho de um governo democrático depende da arrumação de suas partes formais e de que instituições podem moldar suas práticas à medida que estruturam o comportamento, isto é, prepondera o poder e a estratégia de atores políticos.

De outra parte, há uma vertente culturalista que procura ressaltar os aspectos culturais como condicionantes desse desempenho. Para essa vertente, um bom governo depende dos costumes, dos valores de uma sociedade e de suas práticas políticas, especialmente de CS, ou seja, práticas sociais, normas e relações de confiança, que existem entre cidadãos numa determinada sociedade, bem como sistemas de participação e de associação que estimulam a cooperação (Putnam, 2005). O Brasil, entretanto, por sua conformação histórica e política, com a importação de um modelo de Estado hegemônico perante a sociedade, não possibilitou a formação significativa de CS.
Nesse processo dinâmico entre Estado e sociedade, há um amálgama de cidadania que subverte a lógica proposta por Marshall, em que os direitos civis ampliam as liberdades individuais, dando vazão aos direitos políticos de participação na esfera política, e estes, aos direitos sociais, como ocorreu no exemplo inglês. Ao contrário, como coloca Carvalho (2003), no Brasil, houve uma inversão dessa trilogia cidadã, porque primeiro vieram os direitos sociais, depois os políticos e, por fim, os civis. Diferentemente da lógica matemática, a "ordem dos fatores alterou o produto", pois, com a inversão, os direitos sociais passaram a ser vistos como regalias concedidas pelo Estado aos cidadãos, constituindo-se uma espécie de "estatania”, que não só fortaleceu o executivo em detrimento de outras instituições, como o parlamento, mas, sobretudo desarticulou as dinâmicas de pressão da sociedade sobre o Estado. Estabeleceu-se uma relação de clientelismo verticalizada em vez de relações de confiança horizontalizadas. Essa herança histórico-política, que atravessa o período imperial e o republicano no Brasil, terá sérias implicações no final do século XX, quando as reformas implantadas pela Constituição de 1988 passaram a exigir uma nova dinâmica da sociedade brasileira, ou seja, um controle social sobre a esfera política nunca antes demandado.

Nesse sentido, adquire importância fundamental para este trabalho o conceito de CS para se compreender os desafios contemporâneos para a melhora do desempenho do Estado brasileiro em suas diferentes áreas, particularmente na da saúde.

\section{Os Vários Conceitos de Capital Social}

Primeiramente, é preciso dizer que, apesar de o conceito de CS estar em voga nas Ciências Sociais na contemporaneidade, chegando a diversos outros ramos das ciências, como a economia, por exemplo, ou mesmo aos organismos internacionais que fomentam políticas de desenvolvimento no mundo, ele já aparece de forma implícita no século XIX, a partir dos trabalhos de pensadores como Durkheim, Marx, Tocqueville e Simmel. O primeiro entendia que a participação comunitária e a devoção às ações em grupos eram atividades absolutamente necessárias para a integração social e a constituição de uma sociedade organicamente integrada. Deduz-se disso a constituição de uma reserva 
poderosa de capital social, que traria benefícios para o conjunto da sociedade. Durkheim foi bastante explícito nesse ponto, tanto em seu trabalho sobre "A divisão do trabalho social" quanto em "O suicídio".

Em Marx, pode-se perceber de forma implícita a ideia de capital social quando o autor utiliza os conceitos de "consciência de classe em si" e "consciência de classe para si", em que os trabalhadores passariam de uma condição de meros agregados profissionais para outra de consciência de classe explorada proletária. Assim, haveria uma coesão social que surgiria como elemento-resposta para as explorações e as discriminações decorrentes da progressão da industrialização.

0 conceito de capital social também pode ser buscado em Aléxis de Tocqueville, que, mesmo sem usar essa expressão, conseguiu explicitá-la com clareza num estudo comparativo entre a França e os Estados Unidos. Para Tocqueville (2001), o capital social estava diretamente relacionado à sociedade civil organizada, com cultura cívica e liberdade, elementos-chave que também levariam a uma democracia bem-sucedida. Para Simmel, as trocas de informações, os favores interpessoais e o compartilhamento de diferentes tipos de recursos levariam a uma rede de obrigações mútuas e, por consequência, a formação de capital social (Patussi e col., 2006).

Na sequência do século, seguiram-se outros trabalhos de cientistas sociais como Pierre Bourdieu e James Coleman, que reconhecem a importância do capital social para a compreensão da sociedade. Bourdieu (1980), por exemplo, compreende o CS como uma propriedade do agente, como relações sociais que permitem aos indivíduos ou aos grupos obterem recursos ou reconhecimento. Coleman (1988), contrariamente, vê o CS não como uma característica do indivíduo, mas em sentido funcional, como um conjunto de elementos numa estrutura social, que possibilita os atores satisfazerem seus objetivos. Esses elementos são basicamente as obrigações, os canais de informação e as normas e sanções. Muito embora ambos os autores não percam a dimensão da tensão epistêmica entre indivíduo e sociedade no que diz respeito aos dilemas da ação coletiva, poderia se dizer, forçando a análise, que Coleman (1988) inclina-se com seu conceito para a sociedade e Bourdieu (1980) para o indivíduo, ou, em sua própria terminologia, para o "agente".

Seguindo a proposta teórica deste artigo, utili- zou-se a dimensão teórica de CS proposta por Robert Putnam (2005) e Fukuyama (1996), que trabalham a ideia de CS como um bem comunitário. Para Putnam (2005), “capital social” são práticas sociais, normas e relações de confiança que existem entre cidadãos numa determinada sociedade, bem como sistemas de participação e de associação que estimulam a cooperação. Deduz-se dessa conceituação que, quanto maior for a capacidade de os cidadãos confiarem uns nos outros, para além de seus familiares, assim como maior e mais rico for o número de possibilidades associativas numa sociedade, maior será o volume de "capital social”. Assim, a confiança é a expectativa que nasce no meio de uma comunidade de comportamento estável e cooperativo, baseado em normas compartilhadas por esses membros (Fukuyama, 1996). A questão central para Putnam (2005) é que a confiança, a cooperação e os espaços de participação social entre o Estado e a Sociedade são elementos positivos e essenciais para o bom funcionamento das instituições. Não somente para as instituições democráticas, como também as econômicas. Fukuyama (1996) demonstrou que a existência de CS numa sociedade é fator explicativo do tamanho da estrutura industrial ali existente, bem como do desempenho econômico consequentemente.

Putnam (2005) já tinha apontado em seu trabalho "Comunidade e Democracia" que os governos do norte da Itália haviam tido um desempenho institucional superior aos governos do sul cujo volume de CS era menor em comparação com o norte italiano. Em outras palavras, o autor demonstrou como a comunidade cívica e as relações de confiança são importantes variáveis na explicação do desempenho das instituições políticas. No norte italiano, a satisfação com os serviços de educação, saúde, saneamento foram maiores do que no sul, ou seja, os serviços do norte funcionavam melhor que os do sul. Destarte, pode-se ter presente que o CS está relacionado à priorização do interesse coletivo nas relações em sociedade, cuja consecução dá-se de diversas maneiras, dentre as quais a formação de grupos e de associações estáveis, através do compartilhamento de ideias para a obtenção de objetivos comuns e benefício mútuo.

Entretanto, não se pode desconhecer que este conceito necessita ser visto com certa cautela, pois poderá ser utilizado na tentativa de substituir, por exemplo, a responsabilidade dos governos em termos de políticas 
públicas, deixando a organização ou a desorganização da sociedade como a culpada pelos seus problemas e reduzindo o papel do Estado em termos de enfrentamento de desigualdades sociais. Também o fato de já haver muitos conceitos similares já consolidados, tais como desenvolvimento comunitário, sociedade civil, dentre outros, colocaria o capital social como uma repetição de algo já consumado, ou seja, sem ser algo inovador (Souza, 2004). Ao contrário, entende-se que o Estado pode ser um fomentador de CS.

Sendo assim, com base na conceituação de Putnam (2005), fazem-se, neste artigo, algumas considerações sobre seus aspectos positivos no que se refere ao fortalecimento do tecido social, ou seja, o estabelecimento de melhores condições de eficiência do "controle social" sobre as instituições e as políticas públicas da área da saúde, numa conjuntura aberta pela Constituição de 1988, em que há uma exigência cada vez maior da participação efetiva da sociedade nos fóruns de decisão política (consultivas e deliberativas) do Estado.

\section{Capital Social e Controle Social no SUS}

A base de sustentação dessa nova formulação de participação direta e indireta da sociedade civil em fóruns de decisão política é a Constituição Federal de 1988, que trouxe muitos avanços enquanto arcabouço institucional de ampliação dos direitos civis, políticos e sociais. Como argumenta Carvalho (2005), os direitos sociais permitem às sociedades politicamente organizadas reduzirem o excesso de desigualdade produzido pelo capitalismo e garantirem um mínimo de bem-estar para todos.

Assim, o projeto da Reforma Sanitária apontou uma nova atuação da sociedade, demandando uma cidadania participativa que visava romper com uma tradição histórica de centralização do poder estatal e de descaso com os cidadãos. Apostava-se na construção de um país onde a saúde e a democracia fossem elementos inseparáveis e interdependentes, levando, principalmente, à justiça social. Especificamente em relação à saúde, ao processo saúde-doença ou de adoecer e tornar-se saudável, inegavelmente também deveriam ser levados em consideração os aspectos relacionados à forma como a sociedade se organiza social e politicamente e "a forma como ela organiza a produção, a distribuição, o consumo e a utilização de produtos e bens sociais, em conjunto com as condições espaciais, geográfico-territoriais, político-ideológicas e organizativas, enquanto indicadores de riscos ou proteção" (Campana, 2005, p. 7o).

Dessa forma, foram instituídos vários mecanismos que garantiram a participação dos cidadãos nos assuntos do Estado, rompendo com uma tradição elitista e clientelista que sempre privilegiou as relações verticais e proporcionando de forma inovadora o acesso aos fóruns de decisão. Esses instrumentos democráticos foram previstos nas diversas instâncias do governo e nos níveis da federação, através de colegiados com caráter deliberativo ou como instâncias de consulta, objetivando a participação da sociedade civil pela representação de associações legalmente constituídas. Para isso, ganhou importância o "interesse público", qual seja o que deve ser de interesse geral, de todos ou de toda a sociedade, modificando o que foi banalizado como relativo somente ao estatal, sem qualquer conotação com a realização de coisas de interesse geral (Carvalho, 1997).

Diante disso, o SUS traz como uma de suas diretrizes organizacionais a "participação da comunidade" que, neste artigo, caracteriza-se como "controle social”, cuja definição dada na IX Conferência Nacional de Saúde "é a capacidade que tem a sociedade organizada de intervir nas políticas públicas, interagindo com o Estado para o estabelecimento de suas necessidades e interesses na definição das prioridades e metas dos planos de saúde (Brasil, 1992) ou, ainda, segundo Carvalho (1995), o controle social é entendido como uma tentativa de estabelecer uma nova relação entre o Estado e a sociedade, que implica uma abertura do Estado, para que a sociedade participe das suas decisões.

Assim, o papel do Estado se ampliaria para buscar superar uma tradição de privilegiar pequenos grupos em detrimento de camadas mais necessitadas da população e, como diz Carvalho (2005), historicamente, marcadas pela dominação, pelo extermínio, pela doença e pela escravização, fatores que são extremamente negativos para a cidadania e que proporcionam às gerações futuras a continuação de seus infortúnios, sob outras formas, mas de igual amplitude em termos de discriminação e de acesso a condições dignas de vida.

Nesse espaço público democrático, situam-se os conselhos de saúde que, juntamente com as conferências de saúde, propiciam o exercício do controle social no SUS, regulamentado pela lei 8.142/9o - que 
dispõe sobre a participação da comunidade na gestão do SUS e sobre as transferências intergovernamentais de recursos financeiros na área da saúde - e fomentando a participação e a inclusão de diferentes atores sociais. De acordo com essa lei, os conselhos de saúde são órgãos de caráter permanente e deliberativo, isto é, depois de instituídos, devem funcionar por tempo indeterminado, reunindo-se regularmente; têm o direito de tomar decisões relativas à política de saúde a ser executada. Devem formular estratégias, controlar e fiscalizar a execução da política de saúde em sua esfera governamental, inclusive em seus aspectos econômicos e financeiros. As conferências de saúde devem se reunir, em cada nível de governo, em espaços de tempo maiores, mas não superiores a quatro anos, com representantes dos vários segmentos sociais, para avaliar a situação de saúde e propor diretrizes para a formulação da política de saúde da respectiva esfera de governo. Devem ser convocadas pelo Poder Executivo ou, extraordinariamente, também pelo Conselho de Saúde (Carvalho e col., 2001).

Vários aspectos podem ser identificados como protagonistas dessas experiências de controle social no SUS, principalmente a tematização da agenda e da vontade governamental, pela pactuação e construção de interesses comuns. Isso reflete um pacto de bemcomum para a saúde, analisando e acolhendo demandas. Assim, o controle social tem sido considerado elemento-chave da construção social da saúde, pois se constitui num espaço de encontros entre sujeitos sociais portadores de interesses diversos, em que a sociedade vivencia uma relação mais estreita com as estruturas da administração pública e dispõe de um poder direto sobre as decisões governamentais (Mendes, 2005, p. 241-242).

Inegavelmente, nesse contexto de exercício do controle social, pelos conselhos de saúde, e implantação dos fundos de saúde para o seu financiamento, as diversas áreas de atenção e de assistência à saúde conseguiram experimentar avanços pela oferta de procedimentos - tanto curativos quanto preventivos -, pelo acesso universal, pela integralidade, modificando favoravelmente muitos indicadores de saúde em todo o país, a começar pela própria queda da mortalidade infantil, dentre outros.

Ressalte-se que, sob o ponto de vista quantitativo, atualmente, praticamente todos os mais de 5500 municípios brasileiros possuem conselhos de saúde instituídos, que se somam aos dos 27 estados e ao Conselho Nacional de Saúde. No entanto, em termos qualitativos, ainda existe uma longa caminhada a ser percorrida para se chegar ao estágio ideal, que é preconizado na legislação e, principalmente, nos fundamentos da Reforma Sanitária Brasileira, que serviu como base para o controle social e que tinha como significado a ação organizada dos diversos segmentos da população na formulação das políticas e na decisão pública (Carvalho, 2007).

É nessa perspectiva que o conceito de CS adquire relevância para a compreensão do "controle social" sobre o SUS no Brasil. As regiões que mais se desenvolveram no norte italiano apresentaram acúmulo de CS suficiente para que houvesse interesse e participação comunitária nas questões públicas, na busca do bemestar coletivo em oposição ao interesse puramente particular. A ideia de cidadania, em uma comunidade cívica, implica igualdade política, solidariedade, confiança e tolerância. Essa comunidade será tanto mais cívica quanto mais a política se aproximar do ideal de igualdade política entre cidadãos que seguem as regras de reciprocidade e participam do governo, melhorando sua eficiência (Putnam, 2005).

É fundamental que haja uma interação entre a sociedade e o Estado, fazendo com que exista um aprofundamento da democracia dando embasamento social à dimensão institucional, na intenção de democratizar o Estado. A partir disso, o surgimento de organizações não governamentais e de conselhos, por exemplo, pode contribuir para a realização de experiências inovadoras no encaminhamento de problemas sociais, sobretudo nas áreas da educação, da saúde, fortalecendo o tecido social.

A abertura de canais de participação é importante para que se estabeleçam redes de cooperação entre grupos da sociedade, que são fundamentais para que as questões de interesse público sejam enfrentadas e consigam ser transformadas positivamente para todos os cidadãos, através de benefícios que garantam o acesso a políticas públicas de qualidade.

A criação de instituições de defesa de interesses por parte da sociedade civil, segundo Durston (1999), configura-se como elemento destacado para que aconteçam mudanças de valores, comportamentos e atitudes em conformidade com a democracia participativa ou, como 
argumenta Benevides (1994), com uma cidadania ativa, cuja qualidade dos serviços públicos está ligada a sua capacidade de expansão.

Com efeito, esse aparato da sociedade civil sob a denominação de controle social poderá contribuir para a eficácia e a estabilidade da governança democrática não só por seus efeitos "internos" sobre o indivíduo, levando-o à cooperação, mas também devido a seus efeitos "externos" sobre a sociedade e sobre a ação do Estado (cobrando e fiscalizando sua ação) (Figueiredo, 2001)

Entretanto, o Brasil precisa trilhar um longo caminho para superar uma configuração de Estado patrimonialista que facilitou a desigualdade, a heterogeneidade e a estrutura social, e dificultou o acesso a bens de consumo coletivo de responsabilidade estatal, entre eles água potável, moradia, saneamento, energia elétrica, transporte, educação e saúde. Nesse contexto, há muitas distorções no que diz respeito à localização espacial, com grandes diferenças regionais, em que se destacam níveis de pobreza significativos nas regiões Norte/Nordeste e no meio rural, em comparação com outras regiões do país. Todas essas distorções que ainda estão presentes na realidade brasileira devem ser consideradas no acompanhamento da implantação ou da efetivação do CS no SUS, não como fator de desânimo ou de desmobilização, mas como balizador para buscar medidas dinamizadoras em favor de sua qualificação. Daí a hipótese de futuro trabalho, aludindo para o fato de a eficiência do SUS estar diretamente ligada à qualidade da sociedade, ao acúmulo de capital social em uma determinada comunidade. Esta pesquisa de doutorado foi desenvolvida na área de saúde pública buscando verificar empiricamente a consistência de nossa hipótese teórica. Buscou-se constatar em que medida a tese de Putnam (2005) para o caso italiano pode ser generalizada para o caso brasileiro, especialmente no Rio Grande do Sul, onde temos uma diferença nas dotações de CS no estado. No norte, colonizado por imigrantes alemães e italianos, houve o predomínio do minifúndio e da mão de obra não escrava. No sul, com menores dotações do CS, tivemos colonização portuguesa, predominância do latifúndio e da mão de obra escrava, portanto duas configurações diferentes.
Desta maneira, selecionamos para este artigo, duas cidades do Rio Grande do Sul, em que foram implantados o SUS de maneira plena, e que se situam espacialmente em regiões distintas do estado, uma no norte, Caxias do Sul, e outra no sul, Pelotas. Buscamos nos dados empíricos coletados preliminarmente verificar a relação entre o capital social e o desempenho institucional ${ }^{1}$. Em outras palavras, verificar se as dotações de CS em cada cidade guardavam relação com desempenho satisfatório do SUS.

Numa perspectiva comparada, o Gráfico 1 aponta que a população de Caxias do Sul apresenta o maior percentual de confiança interpessoal: 46,3\% responderam sim para o quesito "confiar nas pessoas" e $43,4 \%$ responderam não. Em Pelotas, apenas 12,4\% responderam sim, contra a maioria, $81,4 \%$. que responderam não.

\section{Gráfico I - Confiança interpessoal}

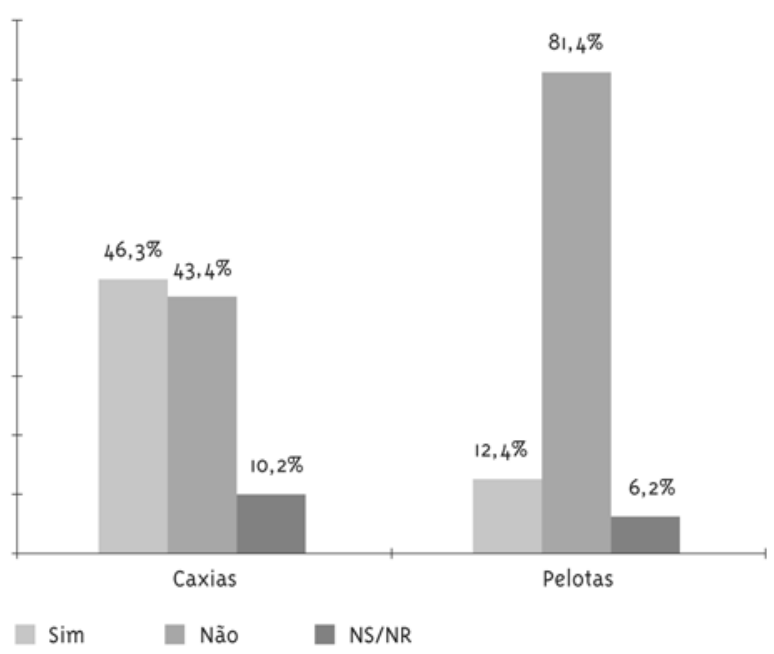

Fonte: do autor.

Total: Caxias do Sul: $\mathrm{N}=244$; Pelotas: $N=169$.

Quando perguntamos sobre a confiança nos vizinhos, os usuários de Caxias apresentaram percentuais maiores: $59 \%$ responderam sim e $23,8 \%$, não; em Pelotas os percentuais foram: $52,8 \%$ para resposta sim e 30,4\% para não. Há, portanto, uma confiança maior nos vizinhos em Caxias do Sul do que em Pelotas. As diferenças percentualmente são significativas no que

1 Foram aplicados dois surveys, com questionários-padrão, em usuários do SUS das cidades de Caxias do Sul e Pelotas a partir de cálculo amostral com base em Taglicarne (1999) com a seguinte fórmula: $n=Z_{2} p(1-p) N /(N-!) e 2+z 2 p(1-p)$. No município de Caxias do Sul foram aplicados 244 e no município de Pelotas 169. 
diz respeito às relações de confiança para além da família, sugerindo que, na cidade de Caxias do Sul os estoques de CS são maiores do que em Pelotas.

\section{Gráfico 2 - Confiança nos vizinhos}

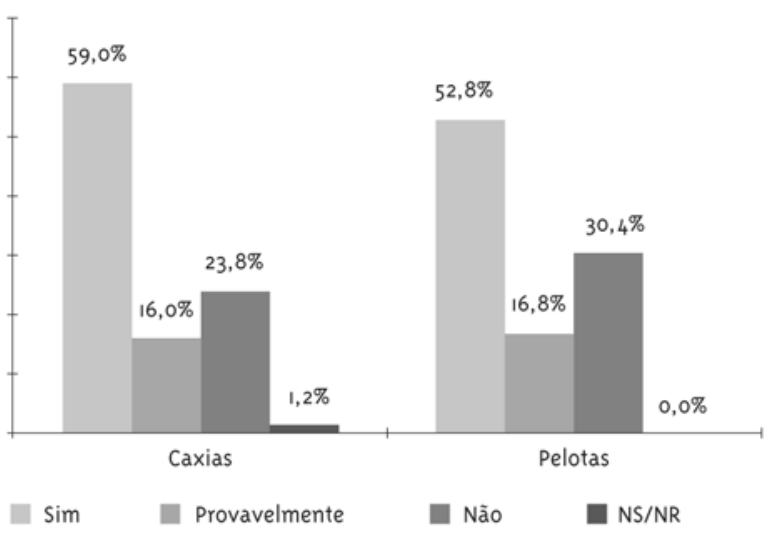

Fonte: do autor

Total: Caxias do Sul: $\mathrm{N}=244$; Pelotas: $\mathrm{N}=169$.

Nesse sentido, o quadro teórico sugere que comunidades, regiões onde os estoques de CS são maiores, haveria uma tendência a um melhor funcionamento das instituições, em nosso caso específico, o sistema de saúde. Corroborando o quadro teórico, no Gráfico 3 quando, avaliamos o sistema odontológico nessas cidades, 93,5\% da população de Caxias do Sul respondeu estar "Muito Satisfeita ou Satisfeita" com o sistema odontológico, contra 6,1\%, da população, que avaliou "Pouco Satisfatório ou Insatisfatório". Em Pelotas o percentual de "Muito Satisfatório e Satisfatório" foi de 81,4\% e "Pouco Satisfatório ou Insatisfatório", 18\%, ou seja duas vezes maior do que em Caxias do Sul.

No que diz respeito, ao grau de institucionalização do sistema, ou seja, o quanto as regras institucionais funcionam, sobrepondo-se às "pessoalidades", apresentamos, no Gráfico 4, que 100\% da população de Caxias do Sul concorda que no atendimento do SUS, "as relações nunca interferem”, inexistindo o percentual dos que concordam que "as relações sempre interferem”. Em Pelotas, diferentemente, 52,8\% da população concorda que "as relações nunca interferem", e 10,6\% concorda que "as relações sempre interferem".

\section{Gráfico 3 - Qualidade do sistema de saúde odonto- lógico}

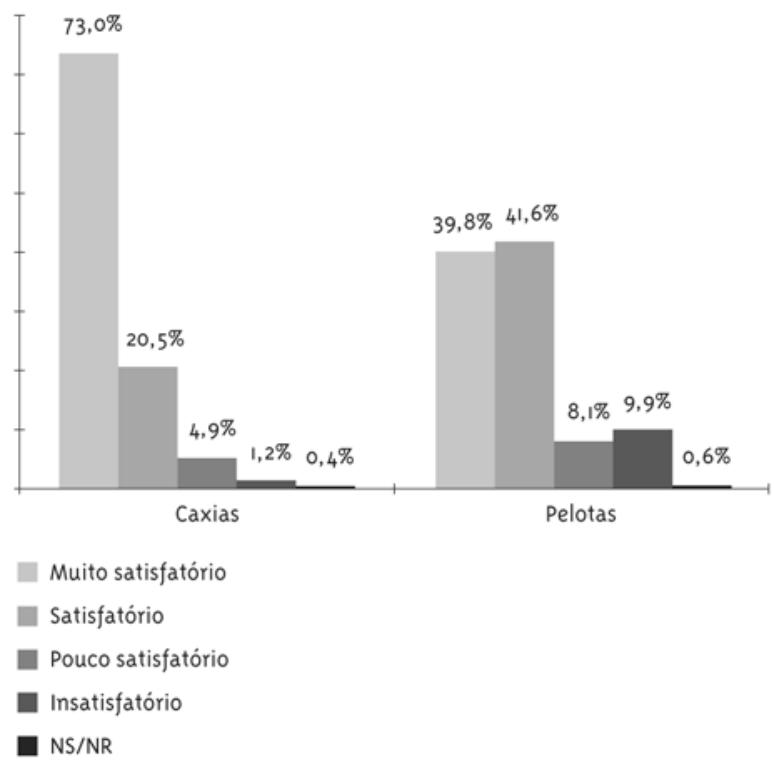

Fonte: do autor

Total: Caxias do Sul: $\mathrm{N}=244$; Pelotas: $\mathrm{N}=169$.

\section{Gráfico 4 - Atendimento no SUS - grau de institucio- nalização}

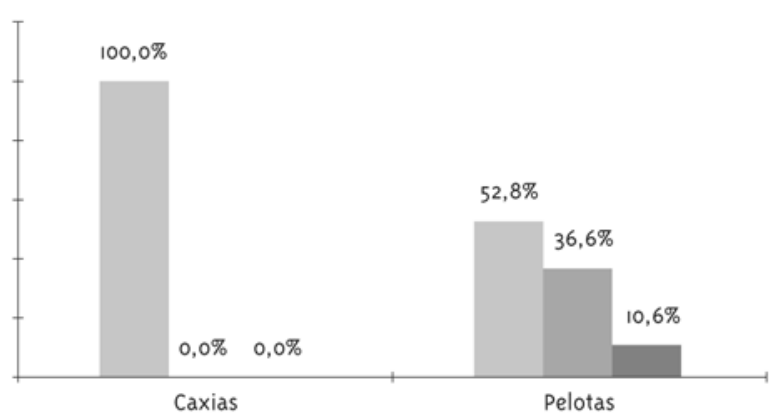

As relações NUNCA interferem

As relações ÀS VEZES interferem

As relações SEMPRE interferem

Fonte: do autor

Total: Caxias $\mathrm{N}=244-$ Pelotas $\mathrm{N}=169$

Reafirmando os dados anteriores, o Gráfico 4 demonstra que o SUS na cidade de Caxias do Sul parece apresentar um funcionamento mais satisfatório do que em Pelotas, a despeito do regramento institucional ser o mesmo em ambas as cidades. 
Como se percebe, portanto, a experiência que se vivencia no Brasil a partir da Constituição de 1988, com o advento do SUS, coloca o Estado como uma importante esfera de promoção da cidadania. Assim, o acúmulo de CS pode dar-se como consequência da existência de redes de cooperação, de associações de interesses, que reforçam a solidariedade e a confiança, facilitando o controle social e o desenvolvimento de ações estatais que beneficiem o conjunto da sociedade e, consequentemente, possibilitem o melhor desempenho das instituições estatais. De outra forma, a abertura, por parte do Estado, de "poros oficiais", espaços de presença permanente e institucional para os diversos segmentos da sociedade em momentos de decisão, também funciona como promotor de solidariedade, que facilita a consolidação da confiança, constituindo-se de espaços privilegiados de reflexão e troca de experiências. Dessa forma, cabe ao Estado propiciar a incorporação de amplos setores sociais com rapidez, buscando suplantar uma herança social excludente, através de políticas que tornem equânime o acesso aos bens e aos serviços públicos, qualificado às relações entre Estado e sociedade (Torres, 2004).

\section{Considerações Finais}

À guisa de conclusão, é preciso reforçar a ideia central defendida neste artigo de que o acúmulo de capital social (CS) em uma determinada sociedade está positivamente relacionado à capacidade de os governos atenderem e realizarem as demandas da população. Além disso, a qualidade das organizações sociais é um dos elementos importantes para o sucesso do funcionamento de instituições como o SUS. Isso é um grande desafio político e histórico, uma vez que a trajetória de formação do Estado no Brasil caracterizou-se por sua forte centralização e hegemonização sobre a sociedade. Contudo, no apagar das luzes do século XX, houve uma inflexão na dinâmica que apontava a democratização de suas esferas, colocando, através de sua descentralização político-administrativa, a sociedade civil num papel protagônico. Esse fato remete às determinações legais, a partir da Constituição de 1988, que foram marcantes e necessárias como bases para todo o desenvolvimento sequencial das outras ações que efeti- vassem um projeto de uma nova sociedade. No entanto, a conquista do que a legislação determina somente se concretizará quando maiores e mais intensas forem as relações sociais que os cidadãos estabelecerem entre si, com suas associações e com a comunidade em geral, ou seja, quanto maior forem os estoques de CS disponíveis na sociedade brasileira. Foi o que procuramos sustentar com nossos dados preliminares da investigação dos casos das cidades gaúchas. Nessa perspectiva, o aumento da eficiência estatal poderá desencadear uma diminuição das desigualdades sociais com a melhor distribuição de serviços públicos aos setores mais subalternizados da sociedade brasileira, caracterizando um círculo virtuoso desejável e necessário na dinâmica relação entre Estado e sociedade no Brasil.

\section{Referências}

BASTOS, F. A. O Consórcio Intermunicipal de Saúde da Região Centro do Estado RS: uma década de história. Porto Alegre: DaCasa, 2005.

BENEVIDES, M. V. Cidadania e democracia. Lua Nova, São Paulo, n. 33, p. 5-16, 1994.

BOURDIEU, P. Le capital social: notes provisoires. Actes de La Recherche en Sciences Sociales, Paris, v. 31, p. 2-3, 1980.

BRASIL. Ministério da Saúde. Gabinete do Ministro. Relatório final da IX Conferência Nacional de Saúde. Brasília, DF, 1992.

CAMPANA, A. Em busca da definição de pautas atuais para o delineamento de estudos sobre condições de vida e saúde. In: KLEBA, M. E. Descentralização do Sistema de Saúde no Brasil: limites e possibilidades de uma estratégia para o empoderamento. Chapecó: Argos, 2005.

CARVALHO, A. I. Conselhos de saúde no Brasil: participação cidadã e controle social. Rio de Janeiro: Fase: Ibam, 1995.

CARVALHO, A. I. Conselhos de saúde, responsabilidade pública e cidadania: a reforma sanitária como reforma do Estado. In: FLEURY, S. T. (Org.). Saúde e democracia: a luta do CEBES. São Paulo: Lemos, 1997. 
CARVALHO, A. I. Os conselhos de saúde, participação social e reforma do Estado. In: KLEBA, M. E.

Descentralização do Sistema de Saúde no Brasil:

limites e possibilidades de uma estratégia para o empoderamento. Chapecó: Argos, 2005.

CARVALHO, A. I. A gestão autoritária cede espaço, pouco a pouco, à práxis democrática. Radis, Rio de Janeiro, n. 53, p. 12-19, 2007.

CARVALHO, B. G.; PETRIS, A. J.; TURINI, B. Controle social em saúde. In: ANDRADE, S. M.; SOARES, D.

A.; CORDONI Jr. L. (Org.). Bases da saúde coletiva. Londrina: UEL: Abrasco, 2001.

CARVALHO, J. M. Cidadania no Brasil: o longo caminho. Rio de Janeiro: Civilização Brasileira, 2003.

COLEMAN, J. S. Social Capital in the Creation of Human Capital. American Journal of Sociology, Chigaco, v. 94, p. 95-120, 1988. Suplemento.

DURSTON, J. Construyendo capital social comunitário. Revista de La Cepal, Santiago, v. 1, n. 69, p. 103-118, 1999.

FAORO, R. Os donos do poder. Porto Alegre: Globo, 1979.

FERRAZ, F. A dimensão histórica da mudança. 0 dilema do profeta. Mimeo, 1993.

FIGUEIREDO, J. E. St. A. Comunidade cívica, capital social e conselhos de saúde no Estado do Rio de Janeiro. 2001. Dissertação - Escola Nacional de Saúde Pública, Fundação Oswaldo Cruz, Rio de Janeiro, 2001.

FUKUYAMA, F. Confiança: as virtudes sociais e a criação da prosperidade. Rio de Janeiro: Rocco, 1996.
MENDES, E. V. Uma agenda para a saúde. In: KLEBA, M. E. Descentralização do Sistema de Saúde no Brasil: limites e possibilidades de uma estratégia para o empoderamento. Chapecó: Argos, 2005.

PATUSSI, M. P et al. Capital social e a agenda de pesquisa em epidemiologia. Cadernos de Saúde Pública, Rio de Janeiro, v. 22, n. 8, p. 1525-1546, 2006.

PUTNAM, R. Comunidade e democracia: a experiência da Itália moderna. Rio de Janeiro: FGV, 2005 .

RIBEIRO, D. O povo brasileiro: a formação e o sentido do Brasil. São Paulo: Companhia das Letras, 2005.

ROUQUIÉ, A. O Estado militar na América Latina. São Paulo: Alfa-Omega, 1984.

SCHWARTZMAN, S. As bases do autoritarismo brasileiro. Rio de Janeiro: Campus, 1988.

SORJ, B. A nova sociedade brasileira. Rio de Janeiro: J. Zahar, 2000.

SOUZA, E. M.; GRUNDY, E. Promoção da saúde, epidemiologia social e capital social: inter-relações e perspectivas para a saúde pública. Cadernos de Saúde Pública, Rio de Janeiro, v. 20, n. 5, p. 13541360, 2004.

TAGLICARNE, G. Pesquisa de mercadologia. São Paulo: Atlas, 1999.

TOCQUEVILLE, A. A democracia na América: leis e costumes. São Paulo: Martins Fontes, 2001. v. 1.

TORRES, M. D. F. Estado, democracia e administração pública no Brasil. Rio de Janeiro: FGV, 2004 . 